\title{
Intensidade de doenças foliares, produtividade, massa de mil grãos e grãos manchados em resposta ao número de aplicações de fungicida no cultivar de arroz irrigado SCS 116 Satoru
}

\author{
Luiz Carlos Bordin ${ }^{1}$, Ricardo Trezzi Casa², Leandro Luiz Marcuzzo ${ }^{3}$, Luis Sangoi², Rômulo Luís Zancan ${ }^{4}$
}

Aluno de Doutorado em Produção Vegetal do Programa de Pós-Graduação em Ciências Agrárias, Centro de Ciências Agroveterinárias - CAV/ UDESC. Av. Luiz de Camões, 2090, CEP 88520-000, Lages, SC; ${ }^{2}$ Professores do Departamento de Agronomia do Centro de Ciências Agroveterinárias - CAV/UDESC. Bolsistas de Produtividade em Pesquisa do CNPq, e-mail: a2rtc@cav.uesc.br; a21s@cav.udesc.br; ${ }^{3}$ Professor do Instituto Federal

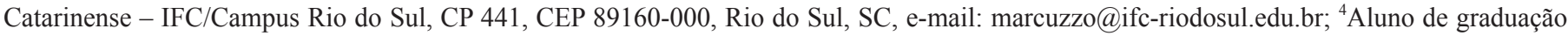
do curso de Agronomia do Centro de Ciências Agroveterinárias - CAV/UDESC. Bolsista de Iniciação Científica - PIBIC/CNPq, e-mail: romulo. zancan@hotmail.com

Autor para correspondência: Luiz Carlos Bordin (luizcarlosbordin@ifc-riodosul.edu.br)

Data de chegada: 28/02/2014. Aceito para publicação em: 03/11/2014.

$10.1590 / 0100-5405 / 1981$

\section{RESUMO}

Bordin, L.C.; Casa, R.T.; Marcuzzo, L.L.; Sangoi, L.; Zancan, R.L. Intensidade de doenças foliares, produtividade, massa de mil grãos e grãos manchados em resposta ao número de aplicações de fungicida no cultivar de arroz irrigado SCS 116 Satoru. Summa Phytopathologica, v.40, n.4, p.329-333, 2014.

A ocorrência de doenças foliares na cultura do arroz irrigado pode reduzir o rendimento e comprometer a qualidade do grão. O objetivo do trabalho foi quantificar a resposta ao número de aplicações de fungicida, na intensidade de doenças foliares, produtividade, massa de mil grãos e grãos manchados em arroz irrigado. Os experimentos foram conduzidos com o cultivar SCS 116 Satoru nas safras 2011/12 e 2012/13, no município de Rio do Oeste, Alto Vale do Itajaí, estado Santa Catarina. O delineamento foi de blocos casualizados, com quatro repetições e seis tratamentos constituídos de aplicações de mistura de fungicidas triazol (difenoconazole) e estrobilurina (azoxistrobina), sendo uma aplicação em final de perfilhamento (V8), duas aplicações (V8 + R0, iniciação da panícula), três aplicações (V8 + R0 + R2, emborrachamento), quatro aplicações (V8 + R0 + $\mathrm{R} 2+\mathrm{R} 4$, floração), cinco aplicações (V8 + R0 + R2 + R4 + R6, grão leitoso) e um tratamento (testemunha) sem aplicação. Antes de cada aplicação foi determinada a incidência e a severidade das doenças foliares. Nas duas safras as doenças foliares predominantes foram brusone, mancha parda e escaldadura. $\mathrm{O}$ aumento de uma até cinco aplicações de fungicida apresenta resposta significativa na redução da intensidade das doenças foliares, com incremento médio de $19,5 \%$, $30 \%, 70,3 \%, 86,6 \%$ e $100,8 \%$ na produtividade, $0,2 \%, 13,7 \%, 28,5 \%, 41,3 \%$ e $54 \%$ na massa de mil grãos e redução de $22 \%, 31,8 \%, 44,1 \%, 75,9 \%$ e $168,5 \%$ de grãos manchados, em relação à testemunha.

Palavras-chave adicionais: Oryza sativa, dano, manchas foliares, qualidade de grãos.

\section{ABSTRACT}

Bordin, L.C.; Casa, R.T.; Marcuzzo, L.L.; Sangoi, L.; Zancan, R.L. Intensity of leaf diseases, productivity, thousand grain weight and spotted grains in response to the number of fungicide applications on irrigated rice cultivar SCS 116 Satoru. Summa Phytopathologica, v.40, n.4, p.329-333, 2014.

The occurrence of leaf diseases in irrigated rice can reduce the yield and the grain quality. The aim of this study was to quantify the response of fungicide application number on leaf disease intensity, productivity, thousand grain weight and spotted grain in irrigated rice. Experiments were conducted with cultivar SCS 116 Satoru in 2011/12 and 2012/13 growing seasons in the city Rio do Oeste, located in Alto Vale do Itajai, Santa Catarina State. Experimental design was in randomized blocks, with four replicates and six treatments constituted of a mixture of fungicides triazole (difenoconazole) and strobilurin (azoxystrobin) in one application at the end of tillering (V8), two applications (V8 + R0, panicle initiation), three applications (V8 + R0 + R2, booting), four applications (V8 + R0 + $\mathrm{R} 2+\mathrm{R} 4$, flowering), five applications (V8 + R0 + R2 + R4 + R6, milky grain) and no application (control). Before each application, the incidence and the severity of leaf diseases were determined. In the two seasons, predominant leaf diseases were blast, brown spot and scald. The increase from one to five fungicide applications presents a significant response in reducing the intensity of leaf diseases, with an average increase of $19.5 \%$, $30 \%, 70.3 \%, 86.6 \%$ and $100.8 \%$ in productivity and $0.2 \%, 13.7 \%, 28.5 \%$, $41.3 \%$ and $54 \%$ in thousand grain weight, as well as a reduction of $22 \%$, $31.8 \%, 44.1 \%, 75.9 \%$ and $168.5 \%$ in spotted grains, compared to control.

Additional keywords: Oryza sativa, damage, leaf spots, grain quality.

O arroz (Oryza sativa L.), cultivado e consumido em todos os continentes, é caracterizado como principal alimento para mais da metade da população mundial, destacando-se, principalmente, em países em desenvolvimento, nos quais, desempenha função estratégica nos níveis econômico e social (21).

A área semeada com arroz irrigado na safra 2012/13 no estado de Santa Catarina foi de aproximadamente 150 mil hectares, com produtividade média de $6.828 \mathrm{~kg} \mathrm{ha}^{-1}(5)$. Porém, esta produtividade 
ainda está abaixo da alcançada em lavouras, que adotam alto nível tecnológico e do potencial produtivo de áreas experimentais, que é de 10 a 12 toneladas ha ${ }^{-1}(4,14)$.

Dentre os fatores limitantes de expressão do potencial produtivo desta cultura, encontram-se as doenças fúngicas foliares que diminuem a área foliar útil das plantas de arroz e, consequentemente, a capacidade da planta de realizar fotossíntese e produzir fotoassimilados, influenciando no enchimento de grãos em plantas infectadas (3). Segundo Balardin \& Borin (2), a ocorrência destas doenças é responsável por danos variáveis entre 20 e $50 \%$ na produtividade.

Dentre as principais doenças fúngicas foliares, nas regiões produtoras de arroz irrigado nos estados do Rio Grande do Sul e Santa Catarina, destacam-se a brusone [Pyricularia grisea (Cooke) Saccardo], mancha parda [Bipolaris oryzae (Breda de Hann) Shoemaker], mancha estreita [Cercospora janseana (Racib) O. Const.] e escaldadura [Gerlachia oryzae (Hashioka \& Yokogi) W. Gams] (19).

A baixa disponibilidade de material genético resistente ao complexo de doenças foliares (19) e o uso intensificado das áreas de cultivo proporcionaram aumento na ocorrência e nos danos causados por doenças fúngicas na orizicultura mundial (17).

Em muitos casos, o controle químico tem sido uma das formas mais viáveis para garantir produtividades e atender a demanda da agricultura (11). A aplicação de fungicidas reduz a severidade de doenças do arroz com aumento de até $42,1 \%$ na produtividade de grãos (7) e manutenção da qualidade de sementes e grãos durante o processo de armazenamento (20).

As indicações técnicas da cultura sugerem até duas aplicações de fungicidas, sendo a primeira no estádio de emborrachamento tardio (até 5\% de emissão de panículas) e a segunda, 10-15 dias após e/ou quando apresentar sintomas das doenças (19). No entanto, numa lavoura de arroz, o complexo de doenças foliares pode iniciar seu crescimento nos primeiros estádios de desenvolvimento da cultura, de forma simultânea, na mesma folha e/ou planta, reduzindo área foliar fotossintetizante e comprometendo o controle químico. Informação precisa e acurada da relação entre intensidade, controle e danos causados pelas doenças foliares são escassas em arroz irrigado.

Diante do exposto, o objetivo do trabalho foi quantificar a resposta ao número de aplicações de fungicida, na intensidade de doenças foliares, produtividade, massa de mil grãos e grãos manchados em arroz irrigado

\section{MATERIAL E MÉTODOS}

Os experimentos foram instalados nas safras agrícolas de 2011/12 e 2012/13, nos mesmos ambientes, em lavouras comerciais, no município de Rio do Oeste, Alto Vale do Itajaí, estado de Santa Catarina.

$\mathrm{Na}$ semeadura, foi utilizado o cultivar SCS 116 Satoru, cujas características são ciclo tardio (de 136 a 159 dias da semeadura à maturação), medianamente resistente à brusone e sem informação para as demais doenças foliares (mancha parda e escaldadura). A semeadura foi no sistema pré-germinado na densidade de $150 \mathrm{~kg} \mathrm{ha}^{-1}$. As adubações de base, a aplicação de adubação nitrogenada, e o controle de plantas invasoras e pragas foram realizados de acordo com as recomendações técnicas para a cultura do arroz no sul do País (19).

Os experimentos foram conduzidos em delineamento de blocos casualizados com quatro repetições. Foram realizados seis tratamentos constituídos de aplicações de mistura de fungicidas triazol (difenoconazole) + estrobilurina (azoxistrobina), dose recomendada pelo fabricante, mais óleo mineral (Nimbus), totalizando 24 parcelas, sendo um dos tratamentos (testemunha) sem aplicação de fungicida. A área correspondente a cada parcela foi de 5,0 × 2,5 metros, com aproximadamente 150 a 180 plantas de arroz por $\mathrm{m}^{2}$.

Os fungicidas foram aplicados em intervalos de 15 a 20 dias, pelo uso de pulverizador costal de pressão constante gerado por gás $\mathrm{CO}_{2}$, com volume de calda de 200 litros ha ${ }^{-1}$.

As aplicações de fungicidas ocorreram nos estádios do perfilhamento (V8), iniciação da panícula (R0), emborrachamento (R2), floração (R4) e grão leitoso (R6), de acordo com a escala de Counce et al. (6), sendo uma aplicação (V8), duas aplicações (V8 + R0), três aplicações (V8 + $\mathrm{R} 0+\mathrm{R} 2)$, quatro aplicações (V8 + R0 + R2 + R4) e cinco aplicações $(\mathrm{V} 8+\mathrm{R} 0+\mathrm{R} 2+\mathrm{R} 4+\mathrm{R} 6)$.

A coleta das folhas para avaliação da incidência e severidade da brusone, mancha parda e escaldadura foi realizada antes de cada aplicação de fungicida, destacando-se três folhas expandidas, do extrato inferior, mediano e superior, em dez plantas ao acaso de cada parcela experimental. Duas pessoas treinadas quantificaram a severidade para evitar possíveis erros sistemáticos, com auxílio de escalas diagramáticas, para brusone (1), escaldadura (9) e mancha parda (12).

$\mathrm{O}$ arroz foi colhido manualmente, coletando-se $2 \mathrm{~m}^{2}$ da parte central de cada parcela. A trilha e a limpeza foram realizadas em máquina estacionária, com posterior secagem dos grãos em estufa até atingir umidade de $13 \%$.

Realizou-se a pesagem dos grãos, determinando-se o rendimento de grãos por parcela e a conversão para hectare. No Laboratório de Fitopatologia do CAV-UDESC, foi realizada a determinação da massa de mil grãos (MMG), pela contagem e pesagem de quatro repetições de 250 grãos por parcela. A determinação da porcentagem de grãos manchados (GM) (> 5\% da área do grão) foi realizada pela pesagem em balança de precisão de GM, em quatro repetições de 50 gramas de grãos por parcela.

Para o cálculo dos danos, que é qualquer redução na qualidade e na quantidade da produção (22), foi obtida de maneira direta através das diferenças das variáveis rendimentos e $\mathrm{MMG}$ entre os tratamentos.

Os resultados obtidos foram submetidos à análise de variância e as médias, comparadas pelo teste de Tukey $(\mathrm{P}<0,05)$, pelo uso do programa estatístico SAS versão 9.2.

\section{RESULTADOS E DISCUSSÃO}

Houve ocorrência concomitante da brusone, mancha parda e escaldadura, com predominância da brusone nas duas safras. Nestas áreas cultiva-se arroz irrigado em monocultura há mais de 30 anos, com históricos destas doenças na região.

A presença das doenças foliares começou a ser observada a partir do início do perfilhamento (V6) e estes dados permitiram determinar a taxa de progressão da epidemia, indicando uma incidência inicial média de $13,3 \%$ e $19,2 \%$, e severidade inicial média de $0,33 \%$ e $0,48 \%$, para as safras 2011/12 e 2012/13, respectivamente.

Os resultados das análises de variância entre os tratamentos foram significativos a $5 \%$ de probabilidade de erro para rendimento $\left(\mathrm{Kg} \mathrm{ha}^{-1}\right)$, massa de mil grãos (g) e grãos manchados (\%).

A intensidade das doenças foliares foi responsiva ao número de aplicação de fungicida, sendo os maiores valores referentes ao tratamento sem aplicação de fungicida (T1 = testemunha), com média de $42,5 \%$ e $1,2 \%$ (safra $2011 / 12$ ) e $72,0 \%$ e $4,3 \%$ (safra 2012/13), e os menores valores para o tratamento com cinco aplicações (T6), com média de $15,1 \%$ e $0,3 \%$ (safra 2011/12) (Tabela 1) e 36,0\% e 1,2\% (safra 2012/13), para incidência e severidade, respectivamente (Tabela 2). 
Tabela 1. Incidência (I) e severidade (S) foliar do patossistema múltiplo brusone, mancha parda e escaldadura no cultivar de arroz irrigado SCS 116 Satoru em resposta à aplicação de fungicida em diferentes estádios de desenvolvimento da planta, safra agrícola de 2011/12, em Rio do Oeste, Alto Vale do Itajaí, SC

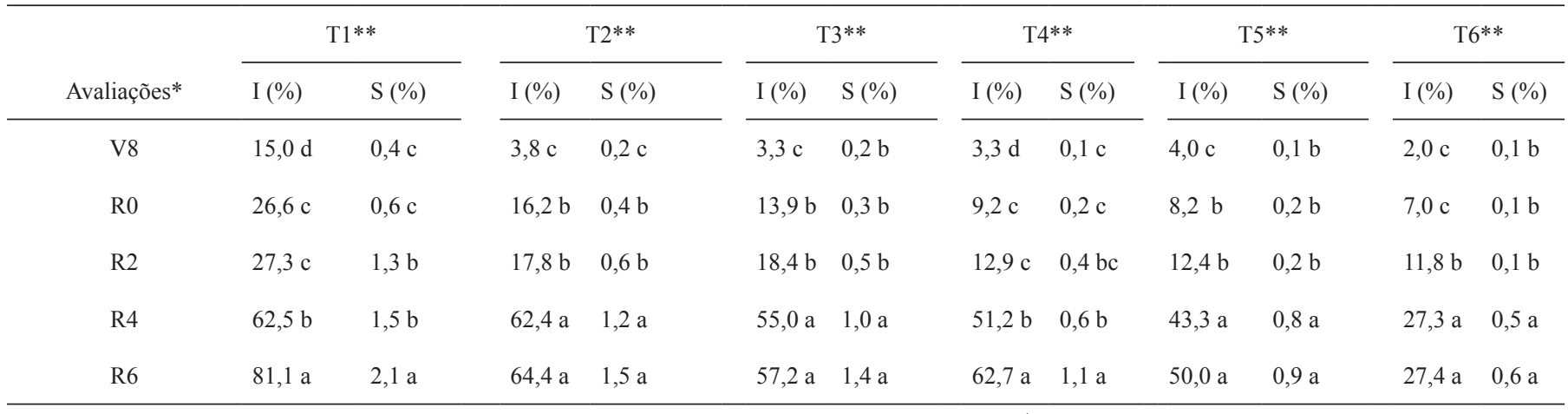

Médias seguidas de mesma letra, nas colunas, não diferem entre si pelo teste de Tukey, ao nível de $5 \%$ de probabilidade. ${ }^{*}$ Avaliações e aplicações de fungicida segundo escala de Counce et al.(2000). **Aplicação fungicida: T1 = sem aplicação de fungicida (testemunha), T2 = uma aplicação (V8), T3 = duas aplicações (V8 + R0), T4 = três aplicações (V8 + R0 + R2), T5 = quatro aplicações $(\mathrm{V} 8+\mathrm{R} 0+\mathrm{R} 2+\mathrm{R} 4)$ e T6 = cinco aplicações $(\mathrm{V} 8+\mathrm{R} 0+\mathrm{R} 2+\mathrm{R} 4+\mathrm{R} 6)$.

Tabela 2. Incidência (I) e severidade (S) foliar do patossistema múltiplo brusone, mancha parda e escaldadura no cultivar de arroz irrigado SCS 116 Satoru em resposta à aplicação de fungicida em diferentes estádios de desenvolvimento da planta, safra agrícola de 2012/13, em Rio do Oeste, Alto Vale do Itajaí, SC

\begin{tabular}{|c|c|c|c|c|c|c|c|c|c|c|c|c|}
\hline \multirow[b]{2}{*}{ Avaliações* } & \multicolumn{2}{|c|}{$\mathrm{T} 1 * *$} & \multicolumn{2}{|c|}{$\mathrm{T} 2 * *$} & \multicolumn{2}{|c|}{$\mathrm{T} 3 * *$} & \multicolumn{2}{|c|}{$\mathrm{T} 4 * *$} & \multicolumn{2}{|c|}{$\mathrm{T} 5 * *$} & \multicolumn{2}{|c|}{$\mathrm{T} 6^{* *}$} \\
\hline & I (\%) & S (\%) & I (\%) & S (\%) & I (\%) & S (\%) & I (\%) & S (\%) & I (\%) & S (\%) & I (\%) & S (\%) \\
\hline R0 & $60,0 \mathrm{~b}$ & $3,5 \mathrm{~b}$ & $50,0 \mathrm{c}$ & $3,0 \mathrm{~b}$ & $50,8 \mathrm{c}$ & $2,4 \mathrm{~b}$ & $46,1 \mathrm{bc}$ & $1,7 \mathrm{~b}$ & $42,3 \mathrm{bc}$ & $1,4 \mathrm{~b}$ & $34,0 \mathrm{~b}$ & $0,9 \mathrm{~b}$ \\
\hline $\mathrm{R} 4$ & $82,4 \mathrm{a}$ & $5,8 \mathrm{a}$ & $74,0 \mathrm{a}$ & $3,5 \mathrm{~b}$ & $68,8 \mathrm{a}$ & $2,8 \mathrm{ab}$ & $52,8 \mathrm{~b}$ & $2,5 \mathrm{a}$ & $54,8 \mathrm{ab}$ & $2,6 \mathrm{a}$ & $40,0 \mathrm{a}$ & $1,4 \mathrm{a}$ \\
\hline R6 & $82,8 \mathrm{a}$ & $6,1 \mathrm{a}$ & 77,9 a & $4,2 \mathrm{a}$ & $76,7 \mathrm{a}$ & $3,3 \mathrm{a}$ & $57,2 \mathrm{a}$ & $3,1 \mathrm{a}$ & $63,7 \mathrm{a}$ & $3,0 \mathrm{a}$ & $44,0 \mathrm{a}$ & $1,7 \mathrm{a}$ \\
\hline
\end{tabular}

Médias seguidas de mesma letra, nas colunas, não diferem entre si pelo teste de Tukey, ao nível de $5 \%$ de probabilidade. *Avaliações e aplicações de fungicida segundo escala de Counce et al.(2000). **Aplicação fungicida: T1 = sem aplicação de fungicida (testemunha), T2 = uma aplicação (V8), T3 = duas aplicações (V8 + R0), T4 = três aplicações (V8 + R0 + R2), T5 = quatro aplicações $(\mathrm{V} 8+\mathrm{R} 0+\mathrm{R} 2+\mathrm{R} 4)$ e T6 = cinco aplicações (V8 + R0 + R2 + R4 + R6).

Na safra 2011/12, observa-se menor intensidade das doenças foliares em relação à safra 2012/13, isto pode ser explicado pela ocorrência de dias consecutivos com alta nebulosidade e molhamento foliar caracterizado de orvalho que caracteriza que as doenças sejam mais agressivas em diferentes safras (8). Consequentemente, a menor intensidade destas doenças também proporcionou maior rendimento de grãos $\left(\right.$ média $\left.=6.444 \mathrm{~kg} \mathrm{ha}^{-1}\right)($ Tabela 3$)$ em relação à safra 2012/13 $\left(\right.$ média $=4.742 \mathrm{~kg} \mathrm{ha}^{-1}$ ) (Tabela 4).

A redução na intensidade das doenças foliares, em relação ao número de aplicação de fungicida, resultou em incrementos significativos na produtividade do arroz. Portanto, o uso de fungicida mostrou-se eficiente no controle de doenças foliares, independentemente do momento da aplicação. Esse resultado corrobora com os de Marzari et al. (15) que concluíram que a diminuição da severidade de doenças pelo controle químico propicia o aumento da produtividade em arroz irrigado.

Esta significância do número de aplicação de fungicida, como fator principal, evidenciou a forte influência das doenças foliares sobre o desempenho produtivo do cultivar SCS 116 Satoru. Estatisticamente, este fato releva que, nos tratamentos com uma (V8) e duas (V8 + R0) aplicações de fungicida, o rendimento de grãos foram inferiores aos demais tratamentos, com $5.575 \mathrm{~kg} \mathrm{ha}^{-1}$ e $5.663 \mathrm{~kg} \mathrm{ha}^{-1}$ (safra 2011/12) e $3.413 \mathrm{~kg} \mathrm{ha}^{-1}$ e $3.988 \mathrm{~kg} \mathrm{ha}^{-1}$ (safra 2012/13), respectivamente. Nas duas safras, três, quatro e cinco aplicações de fungicida resultaram em acréscimo de $70,3 \%, 86,6 \%$ e $100,8 \%$ (média $=85,9 \%$ ) no rendimento de grãos. Na análise da ausência de fungicida, a severidade de infecção pelos patógenos e as médias de rendimento de grãos, evidenciam a suscetibilidade deste cultivar, com rendimento de $4.388 \mathrm{~kg} \mathrm{ha}^{-1} \mathrm{e} 3.050$ $\mathrm{kg} \mathrm{ha}^{-1}$ (Tabelas 3 e 4). Segundo Jiao \& Li (10) o uso de fungicida fazse importante para a proteção da área foliar das plantas, mantendo-as fotossinteticamente ativa, principalmente em condições de elevada severidade de doenças.

Os danos avaliados neste trabalho referente ao tratamento com cinco aplicações em relação aos demais, foram de 11,3 a 49,1\% (safra 2011/12) (Tabelas 3) e 3,0 a 51,2\% (safra 2012/13) (Tabela 4). Estes resultados revelam a magnitude do dano causado pelas doenças foliares e corroboram com Dallagnol et al. (7), que relataram que a aplicação de fungicidas reduz a severidade de doenças em arroz irrigado, resultando em aumento da produtividade de grãos na ordem de 6,1 a $42,1 \%$.

Comportamento semelhante ocorreu para a massa de mil grãos (MMG). O aumento do número de aplicações de fungicida ocorreu na redução das doenças e isto, resultou em incrementos significativos na MMG. O aumento da produtividade do arroz irrigado está relacionado ao melhor enchimento de grãos, observado no efeito da aplicação de 
Tabela 3. Rendimento, massa de mil grãos (MMG) e porcentagem de grãos manchados (GM) no cultivar de arroz irrigado SCS 116 Satoru em resposta ao número de aplicação de fungicidas em diferentes estádios de desenvolvimento da planta, na safra agrícola de 2011/12, em Rio do Oeste, Alto Vale do Itajaí, SC

\begin{tabular}{|c|c|c|c|c|c|}
\hline Tratamento & $\begin{array}{l}\text { Rendimento } \\
\qquad\left(\mathrm{kg} \mathrm{ha}^{-1}\right)\end{array}$ & $\begin{array}{l}\text { Dano } \\
(\%)\end{array}$ & $\begin{array}{c}\text { MMG } \\
\text { (g) }\end{array}$ & $\begin{array}{l}\text { Dano } \\
(\%)\end{array}$ & $\begin{array}{l}\text { GM } \\
(\%)\end{array}$ \\
\hline Sem fungicida & $4.388 \mathrm{c}$ & 49,12 & $19,22 \mathrm{c}$ & 29,49 & 19,78 a \\
\hline Uma aplicação* & $5.575 \mathrm{bc}$ & 35,36 & $19,69 \mathrm{bc}$ & 27,77 & $13,75 \mathrm{~b}$ \\
\hline Duas aplicações* & $5.663 \mathrm{bc}$ & 34,34 & $20,84 \mathrm{bc}$ & 23,55 & $12,10 \mathrm{bc}$ \\
\hline Quatro aplicações* & $7.650 \mathrm{a}$ & 11,30 & $25,53 \mathrm{a}$ & 6,34 & $9,42 \mathrm{~d}$ \\
\hline Cinco aplicações* & $8.625 \mathrm{a}$ & -- & $27,26 \mathrm{a}$ & -- & $5,28 \mathrm{e}$ \\
\hline Média & 6.444 & 30,34 & 22,4 & 21,38 & 11,8 \\
\hline C.V. $(\%)$ & 13,14 & -- & 4,67 & -- & 9,01 \\
\hline
\end{tabular}

Médias seguidas de mesma letra, nas colunas, não diferem entre si pelo teste de Tukey, ao nível de 5\% de probabilidade. *Aplicação fungicida: uma aplicação (V8), duas aplicações (V8 + R0), três aplicações (V8 + R0 + R2), quatro aplicações (V8 + R0 + R2 + R4) e cinco aplicações (V8 + R0 + R2 + R4 + R6), segundo escala de Counce et al. (2000).

Tabela 4. Rendimento, massa de mil grãos (MMG) e porcentagem de grãos manchados (GM) no cultivar de arroz irrigado SCS 116 Satoru em resposta ao número de aplicação de fungicidas em diferentes estádios de desenvolvimento da planta, na safra agrícola de 2012/13, em Rio do Oeste, Alto Vale do Itajaí, SC

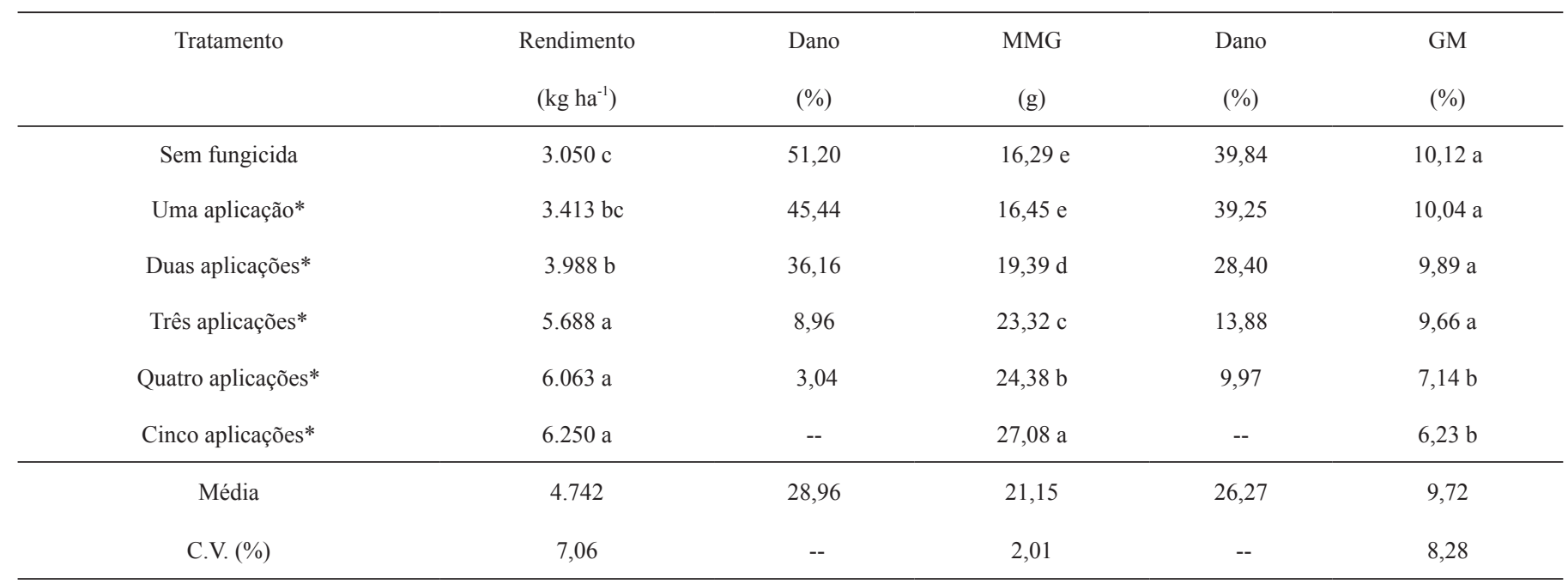

Médias seguidas de mesma letra, nas colunas, não diferem entre si pelo teste de Tukey, ao nível de 5\% de probabilidade. *Aplicação fungicida: uma aplicação (V8), duas aplicações (V8 + R0), três aplicações (V8 + R0 + R2), quatro aplicações (V8 + R0 + R2 + R4) e cinco aplicações (V8 + R0 + R2 + R4 + R6), segundo escala de Counce et al. (2000).

fungicida na massa de mil grãos. As doenças foliares causam redução de área fotossintética e a proteção da área foliar resulta na manutenção da capacidade de produzir fotoassimilados, evitando danos no enchimento dos grãos. Sofiatti \& Schuch (18) destacam que a aplicação de fungicida proporciona maior produção de fotoassimilados favorecendo o enchimento dos grãos.

Quanto à percentagem de grãos manchados (GM), em ambas as safras houve resposta positiva número de aplicações de fungicida.

Na safra 2011/12, a variação dos grãos manchados foi de 5,3\% a $19,8 \%$ (Tabela 3 ) e para safra $2012 / 13$, variações de $6,2 \%$ a $10,1 \%$ (Tabela 4).

Os maiores percentuais na safra 2012/13 (média $=11,8 \%$ ), foi devido à maior incidência da mancha parda, que, segundo Prabhu \& Filippi (16), é considerada uma das principais doenças causadoras de manchas nos grãos de arroz.

Os tratamentos que apresentaram maior intensidade de doenças foliares também revelaram maior percentual de grãos manchados, evidenciando a importância das lesões nas folhas como fonte de inóculo para os grãos. Esta avaliação faz-se importante porque, segundo Malavolta et al. (13), a emergência e a sobrevivência de plântulas de arroz são inversamente proporcionais à incidência de manchas nas sementes, que podem afetar o estande inicial da lavoura, favorecendo o desenvolvimento de epidemias.

Fazendo uma análise econômica de custo/benefício, toma-se como exemplo na safra 2012/13, o tratamento T4 (três aplicações de fungicidas) em relação ao tratamento T3 (duas aplicações, sugerido pelas Indicações Técnicas/SOSBAI). O custo de controle na cultura do arroz irrigado é aproximadamente R \$100,00/hectare e o preço de venda da saca de arroz R \$ 31,00 (Fonte: Cooperativa Regional Agropecuária Vale do Itajaí - CRAVIL/Rio do Sul/SC/setembro de 2013), temos um incremento de $1.700 \mathrm{Kg} \mathrm{ha}^{-1}$ (34 sacas). Substituindo, tem-se: 34 sacas x R\$ 31,00 = R\$ 1.054,00 - R \$ 100 (uma aplicação a mais de fungicidas) com receita líquida $\mathrm{R} \$ 954 /$ hectare (Tabela 5). Portanto, o uso de fungicida mostra-se eficiente no controle de doenças foliares com 
Tabela 5. Análise econômica referente ao número e custo das aplicações de fungicida, rendimento de grãos, receita bruta e líquida, obtido pelo manejo químico no controle de doenças foliares em arroz irrigado, cultivar SCS 116 Satoru, na safra agrícola de 2012/13, em Rio do Oeste, Alto Vale do Itajaí, SC

\begin{tabular}{|c|c|c|c|c|}
\hline Tratamento $^{1}$ & $\begin{array}{l}\text { Custo da } \\
\text { Aplicação } \\
\left(\mathrm{R} \$ \mathrm{ha}^{-1}\right)\end{array}$ & $\begin{array}{l}\text { Rendimento } \\
\left(\mathrm{Kg} \mathrm{ha}^{-1}\right)\end{array}$ & $\begin{array}{c}\text { Receita } \\
\text { Bruta }^{3} \\
\left(\mathrm{R} \$ \mathrm{ha}^{-1}\right)\end{array}$ & $\begin{array}{c}\text { Receita } \\
\text { líquida } \\
\left(\mathrm{R} \$ h \mathrm{a}^{-1}\right)\end{array}$ \\
\hline Uma aplicação* & 100,00 & 3.413 & 2.116 & 2.016 \\
\hline Duas aplicações* & 200,00 & 3.988 & 2.473 & 2.273 \\
\hline Três aplicações* & 300,00 & 5.688 & 3.527 & 3.227 \\
\hline Cinco aplicações* & 500,00 & 6.250 & 3.875 & 3.375 \\
\hline
\end{tabular}

1*Aplicação fungicida: uma aplicação (V8), duas aplicações (V8 + R0), três aplicações (V8 + R0 + R2), quatro aplicações (V8 + R0 + R2 + R4) e cinco aplicações (V8 + R0 + R2 + R4 + R6), segundo escala de Counce et al. (2000).

${ }^{2}$ Custo da Aplicação = R \$ 100,00; ${ }^{3}$ Preço de venda do arroz em setembro/2013 (R\$ 31,00 / saco ou R \$ 620,00 tonelada) (Fonte: CRAVIL /Rio do Sul).

retorno econômico em relação ao número de aplicação de fungicida.

Os efeitos no controle das doenças foliares e, consequentemente, na produtividade estão relacionados com a frequência de aplicação do produto. $\mathrm{O}$ efeito residual do produto quando aplicado uma (final do perfilhamento) e duas vezes (final do perfilhamento e iniciação da panícula) não é suficiente para controle da doença até o final do ciclo. A redução significativa na severidade das doenças proporcionada pelo controle químico evidencia a importância de conhecer e estabelecer estratégias quanto ao momento da aplicação de fungicida visando estabilidade da produção de grãos.

A eficiência de controle das doenças foliares do arroz e o acréscimo nos componentes de rendimento são evidentes quando realizadas três, quatro e cinco aplicações de fungicidas, por reduzir significativamente a intensidade da brusone, mancha parda e escaldadura, principalmente nos estádios reprodutivos R2, R4 e R6 e proporciona um incremento no rendimento de grãos e redução na percentagem de grãos manchados.

\section{REFERÊNCIAS BIBLIOGRÁFICAS}

1. Azevedo, L.A.S. Manual de quantificação de doenças de plantas. São Paulo: Novartis Biociências, 1997. 11 p.

2. Balardin, R.S.; Borin, R.C. Doenças na cultura do arroz irrigado. Santa Maria: UFSM, 2001. 48p.

3. Bedendo, I.P. Doenças do arroz. In: Kimati, H.; Amorim, L. Manual de fitopatologia. São Paulo: Agronômica Ceres, 1997. cap 10, p. 85-99.

4. Bordin, L.C.; Casa, R.T.; Gheller, A.; Marcuzzo, L.L.; Fontana Junior, F.; Colla Junior, G. Influência do número de aplicações de fungicidas sobre o rendimento dos cultivares de arroz irrigado Epagri 109 e SCS 116 Satoru no Alto Vale do Itajaí/SC. In: Congresso Brasileiro de Arroz Irrigado, 7., 2011, Balneário Camboriú. Anais...Itajaí : Epagri 2011. v.1, p. 547-550.

5. Companhia Nacional de Abastecimento. Acompanhamento de safra brasileira: grãos, $9^{\circ}$ levantamento, Brasília, 2013.

6. Counce, P.; Keisling, T.C.; Mitchell, A.J.A uniform, objective, and adaptive system for expressing rice development. Crop Science, Madison, v.40, n.2, p. 436-443, 2000.

7. Dallagnol, L.J.; Navarini, L.; Balardin, R.S.; Gosenheime, A.; Maffini, A.A. Danos das doenças foliares na cultura do arroz irrigado e eficiência de controle dos fungicidas. Revista Brasileira Agrociência, Pelotas, v. 12, n. 3, p. 131-318. 2006.

8. Epagri. Atlas climatológico do estado de Santa Catarina. Florianópolis: Disponível em: http://ciram.epagri.sc.gov.br/portal/website/ Online. Acesso em: 20 nov. 2013.
9. International Rice Research Institute. Standard evaluation system for rice. $4^{\text {nd }}$ ed. Manila. 1996. $52 \mathrm{p}$.

10. Jiao, D.; Li, X. Characteristics of chlorophyll fluorescence and membranelipid peroxidation during senescence of flag leaf in different cultivars of rice. Photosynthetica, Prague, v. 41, n. 3, p. 33-41, 2003.

11. Kimati, H. Controle químico. In: Bergamin Filho, A.; Kimati, H.; Amorim, L. (Ed.) Manual de fitopatologia: princípios e Conceitos. 3. Ed. São Paulo: Agronômica Ceres, 1995. v.1, 919p.

12. Lenz, G.; Balardin, R.S.; Dala Corte, G.; Marques, L.N.; Debona, D. Escala diagramática para avaliação de severidade de mancha-parda em arroz. Ciência Rural, Santa Maria, v.40, n.4, p.752-758, 2010.

13. Malavolta, V.M.A.; Parisi, J.J.D.; Takada, H.M. Efeito de diferentes níveis de incidência de Bipolaris oryzae em sementes de arroz sobre aspectos fisiológicos da semente, transmissão do patógeno as plântulas e produção. Summa Phytopathologica, Jaboticabal, v. 28, n. 4, p. 336-340, 2002.

14. Mariot, C.H.P.; Silva, P.R.F.; Menezes, V.G.; Teichmann, L.L. Resposta de duas cultivares de arroz irrigado à densidade de semeadura e à adubação nitrogenada. Pesquisa Agropecuária Brasileira, Brasília, v. 38, n. 2, p. 233-241, 2003.

15. Marzari, V.; Marchezan, E.; Silva, L.S.; Camargo, E.R.; Teló, G.M. População de plantas, dose de nitrogênio e aplicação de fungicida na produção de arroz irrigado: I - características agronômicas. Ciência Rural, Santa Maria, v. 37, p. 330-336, 2007.

16. Prabhu, A.S.; Filippi, M.C.C. Arroz (Oryza sativa L.) controle de doenças. In: Vale, F.X.R.; Zambolim, L. (Ed.) Controle de doenças de plantas: grandes culturas. Viçosa: Universidade Federal de Viçosa, 1997. v. 1, p. 51-79.

17. Prabhu, A.S.; Filippi, M.C.C.; Ribeiro, A.S. Doenças e seu controle. In: Santo, A.B.; Stone, L.F.; Vieira, N.R.A. (Ed.). A cultura do arroz no Brasil. 2. ed. Santo Antônio de Goiás: EMBRAPA/CNPAF, 2006. p. 561-590.

18. Sofiatti, V.; Schuch, L. O. B. Efeitos de regulador de crescimento, controle de doenças e densidade de semeadura na qualidade industrial de grãos de arroz. Ciência Rural, Santa Maria, v. 36, n. 2, p. 418-423, 2006.

19. Sosbai. Arroz Irrigado: recomendações técnicas da pesquisa para o Sul do Brasil. In: Reunião Técnica da Cultura do Arroz Irrigado, 29., 2012, Itajaí. Anais...Itajaí: Sociedade Sul-Brasileira de Arroz Irrigado, 2012. 179p.

20. Teló, G.M.; Marchezan, E.; Ferreira, R.B.; Menezes, N. L.; Hansel, D.S.S.; Sartori, G.M.S. Aplicação de fungicida em plantas de arroz irrigado e seu efeito na qualidade de sementes durante o armazenamento. Revista Brasileira de Sementes, Londrina, v. 34, n.1, 2012.

21. Walter, M.; Marchezan, E.; Ávila, L.A. Arroz: composição e características nutricionais. Ciência Rural, Santa Maria, v. 38, n. 4, p. 1184-1192, 2008.

22. Zadoks, J.C.; Schein, R.D. On the conceptual basis of crop loss assessment: the threshold theory. Annual Review of Phytopathology, Palo Alto, (US), v. 23 , p. $455-473,1985$. 